\title{
DENSIDADE, ÍNDICE DE REFRAÇÃO E EQUILÍBRIO LÍQUIDO-LÍQUIDO DO SISTEMA MODELO ÓLEO DE SEMENTE DE GIRASSOL + N-HEXANAL + LACTATO DE ETILA A $20^{\circ} \mathrm{C}$ SOB PRESSÃO ATMOSFÉRICA
}

\author{
D. S. S. JORQUEIRA, P.O.B. HOMRICH, R. CERIANI ${ }^{1}$ \\ ${ }^{1}$ Universidade Estadual de Campinas, Faculdade de Engenharia Química \\ E-mail para contato: rceriani@feq.unicamp.br
}

\begin{abstract}
RESUMO - Para se tornar comestível, o óleo de semente de girassol passa pelo processo de refino químico para remoção da acidez e de compostos minoritários. Dentre as etapas do refino químico, está a desodorização, que remove compostos odoríferos formados pela oxidação do óleo, além de contaminantes, como os pesticidas. A desodorização é um processo de esgotamento com arraste a vapor que emprega altas temperaturas (até $265^{\circ} \mathrm{C}$ ) e baixas pressões (até $3 \mathrm{mmHg}$ ), sendo essas condições drásticas de processamento responsáveis pela degradação térmica e/ou volatilização de compostos nutracêuticos (principalmente antioxidantes), além de reações de oxidação e isomerização cis-trans de ácidos graxos insaturados. A fim de evitar tais consequências indesejáveis, esse trabalho teve como objetivo investigar a viabilidade de aplicação da extração por solvente na desodorização do óleo vegetal. Assim, foi obtida a curva binodal do sistema pseudoternário constituído por óleo de semente de girassol (diluente) + n-hexanal (soluto) + lactato de etila (solvente) a $20^{\circ} \mathrm{C}$. As linhas de amarração foram quantificadas pelo método da regra da alavanca, sendo a qualidade dos dados experimentais verificada pelos testes de Othmer-Tobias e Hand.
\end{abstract}

\section{INTRODUÇÃO}

Uma das etapas cruciais do refino dos óleos vegetais é a desodorização, a qual promove a remoção de compostos odoríferos, bem como de compostos minoritários presentes no óleo, como pesticidas. Por operar com condições que envolvem alta temperatura (até $265^{\circ} \mathrm{C}$ ) e baixas pressões (até $3 \mathrm{mmHg}$ ), a desodorização acarreta na perda de compostos nutracêuticos, degradação dos triacilgliceróis, como também as reações de oxidação e isomerização cis-trans (HAMM, 2003). Desta forma, faz-se necessária a busca por um meio alternativo mais brando de desodorizar os óleos vegetais, resultando num refino menos agressivo ao óleo.

A literatura apresenta como alternativa à desacidificação dos óleos vegetais por via física, a extração dos ácidos graxos livres utilizando um solvente, através da extração líquido-líquido (Batista et al., 1999; Rodrigues et al., 2007). Podendo operar a temperaturas amenas (cerca de $25^{\circ} \mathrm{C}$ ) e sob pressões atmosféricas, a remoção dos compostos de interesse (solutos) se dá pela solubilização destes em um terceiro componente (solvente), o qual preferencialmente deve ser pouco solúvel no diluente (óleo vegetal), resultando numa menor perda de óleo na corrente de solvente. Os estudos investigaram uma gama de óleos vegetais (soja, arroz, girassol, palma, 
dentre outros), bem como vários solutos (ácido oleico, linoleico, palmítico, etc), e verificaram que o melhor solvente para desacidificar o óleo foi o etanol (Gonçalves; Meirelles, 2004; Cuevas; Rodrigues; Meirelles, 2009).

A fim de projetar o processo de extração líquido-líquido, deve ser investigada a solubilidade mútua dos compostos do sistema, sendo necessária a elaboração de diagramas de fases. Contudo, uma das etapas que apresenta maior complexidade é a quantificação das fases em equilíbrio, a qual possibilita a determinação das linhas de amarração que relacionam as concentrações mássicas da mistura inicial com as das fases refinado (rica em óleo vegetal fase I) e extrato (rica em solvente - fase II). Desta forma, estudos previamente realizados determinaram métodos que possibilitam uma quantificação menos custosa e laboriosa, como o método da regra da alavanca (Merchuk; Andrews; Ansejo, 1998), o qual, pela determinação de uma relação existente entre as frações mássicas da curva binodal do sistema de interesse juntamente com as relações oriundas da regra da alavanca, permite que a composição de cada fase em equilíbrio seja facilmente determinada.

Frente ao exposto, esse trabalho objetivou determinar o equilíbrio líquido-líquido formado pelo sistema modelo óleo de semente de girassol (1) + n-hexanal (2) e lactato de etila (3) a $20{ }^{\circ} \mathrm{C}$ e sob pressão atmosférica pelo metodologia do ponto de névoa, sendo a quantificação das fases realizada pelo método da regra da alavanca. Além disso, foram determinadas a densidade e o índice de refração dos sistemas ternários na curva binodal a 20 ${ }^{\circ} \mathrm{C}$. A qualidade dos dados experimentais foi verificada utilizando os testes de Othmer-Tobias (1942) e Hand (1930).

\section{MATERIAIS E MÉTODOS}

\subsection{Materiais}

O n-hexanal e o lactato de etila foram adquiridos da Sigma Aldrich, ambos apresentando uma pureza de 99,8\%. Já o óleo de semente de girassol utilizado foi da marca Lisa ${ }^{\circledR}$, adquirido em estabelecimento local. Para as medidas de índice de refração, utilizou-se um refratômetro (Mettler-Toledo $\AA$, modelo RE 40D), e para a densidade, utilizou-se um densímetro (Anton-Paar ${ }^{\circledR}$, modelo DMA 5000). Para a constância da temperatura, utilizou-se um banho termostático (Technal ${ }^{\circledR}$, modelo TE 2005). As propriedades físicas dos componentes puros estão apresentadas na Tabela 1.

Tabela 1 - Densidade e índice de refração para as substâncias puras a 293,15 K.

\begin{tabular}{|c|c|c|c|c|}
\hline Componente & $\rho\left(\mathrm{g} / \mathrm{cm}^{3}\right)$ & $\sigma^{\mathrm{a}}\left(\mathrm{x} 10^{-4}\right)$ & $\mathrm{nD}$ & $\sigma^{\mathrm{a}}\left(\mathrm{x} 10^{-4}\right)$ \\
\hline 1: Óleo de Semente de Girassol & 0,92041 & 5,3 & 1,4741 & 0,6 \\
\hline 2: n-Hexanal & 0,82104 & 0,2 & 1,4058 & 1,5 \\
\hline 3: Lactato de Etila & 1,03345 & 3,8 & 1,4126 & 0,0 \\
\hline
\end{tabular}

a: $\sigma$ : triplicata obtida entre as medidas das propriedades físicas.

\subsection{Procedimento Experimental}

Obtenção de Ponto de Névoa e Curvas de Calibração: Para obtenção experimental dos pontos de névoa, foi utilizada uma célula de vidro encamisada contendo as espécies químicas, 
previamente pesadas em uma balança analítica (AS 220/C/2 Radwag). Externamente à célula, foi circulada água a $20{ }^{\circ} \mathrm{C}$, através de um banho termostático. A célula continha inicialmente lactato de etila $+n$-hexanal ou óleo $+n$-hexanal, sendo as misturas vigorosamente agitadas utilizando agitadores magnéticos (Fisatom, modelo 752). Visualmente, o ponto de névoa, verificado pela turbidez da mistura, foi determinado gotejando o terceiro composto (óleo ou lactato de etila) através de uma seringa. Quando detectou-se a turbidez da mistura, esperou-se um período de 10 minutos a fim de verificar a permanência da turbidez, confirmando a obtenção do ponto da curva binodal. Esse procedimento foi realizado seis vezes em duplicata para cada lado da curva de solubilidade.

Para cada amostra do ponto de névoa, foram determinadas a densidade e o índice de refração a $20{ }^{\circ} \mathrm{C}$, a fim de verificar o comportamento dessas propriedades ao longo da curva binodal. Já os dados da fração mássica do n-hexanal (2) provenientes da curva binodal foram relacionados em função da fração mássica do lactato de etila (3) por uma equação polinomial de sexto grau para a fase refinado (Eq. 1) e para a fase extrato (Eq. 2). Vale ressaltar que os parâmetros dessas equações são os mesmos, porém, pelo fato de não terem sido determinados os pontos na região do plait point, houve a necessidade de representar os polinômios separadamente para cada fase do sistema. Essas equações serviram para posterior quantificação das linhas de amarração pelo método da regra da alavanca.

$$
\begin{aligned}
& w_{2}^{I}=A+B \cdot w_{3}^{I}+C \cdot\left(w_{3}^{I}\right)^{2}+D \cdot\left(w_{3}^{I}\right)^{3}+E \cdot\left(w_{3}^{I}\right)^{4}+F \cdot\left(w_{3}^{I}\right)^{5}+G \cdot\left(w_{3}^{I}\right)^{6} \\
& \left.w_{2}^{I I}=A+B \cdot w_{3}^{I I}+C \cdot\left(w_{3}^{I I}\right)^{2}+D \cdot\left(w_{3}^{I I}\right)^{3}+E \cdot\left(w_{3}^{I I}\right)^{4}+F \cdot\left(w_{3}^{I I}\right)^{5}+G\right) \cdot\left(w_{3}^{I I}\right)^{6}
\end{aligned}
$$

Determinação das linhas de amarração e teste de qualidade dos dados: A fim de obter as linhas de amarração do sistema investigado, foram preparados três pontos de mistura nos quais as frações mássicas dos componentes estavam contidas na região heterogênea do diagrama de fases, assegurando a separação de fases. As misturas ternárias foram vigorosamente agitadas com um agitador magnético por um período de 2 horas, sendo que posteriormente as misturas decantaram por um período de 12 horas, permitindo a completa separação das fases.

Para a quantificação usando o método da regra alavanca, as massas das fases foram cuidadosamente mensuradas e relacionadas com as relações provenientes da regra da alavanca, como apresentam as Equações 3 e 4.

$$
\begin{aligned}
& w_{2}^{I I}=\frac{w_{2}^{M}}{\alpha}+\left(\frac{1-\alpha}{\alpha}\right) w_{2}^{I} \\
& w_{3}^{I I}=\frac{w_{3}^{M}}{\alpha}+\left(\frac{1-\alpha}{\alpha}\right) w_{3}^{I}
\end{aligned}
$$

Nas Equações 3 e 4, $w_{2}^{I}$ e $w_{3}^{I}$ são as frações mássicas do soluto e do solvente na fase refinado, sendo $w_{2}^{I}$ oriundo da Equação $1, w_{2}^{I I} \mathrm{e} w_{3}^{I I}$ são as frações mássicas do soluto e do solvente na fase extrato. Já $w_{2}^{M}$ e $w_{3}^{M}$ são as frações mássicas do soluto e do solvente na 
mistura inicial. Por fim, $\alpha$ representa a razão entre a massa da fase extrato (em gramas) e a massa da mistura inicial (em gramas). A qualidade dos dados experimentais das frações mássicas das fases em equilíbrio nas linhas de amarração foi atestada pelo método de OthmerTobias.

\section{RESULTADOS}

\subsection{Curva Binodal e curvas de calibração}

$\mathrm{Na}$ Tabela 2 estão apresentadas as porcentagens mássicas da curva binodal para o sistema óleo de semente de girassol (1), n-hexanal (2) e lactato de etila (3) a $20{ }^{\circ} \mathrm{C}$, bem como as propriedades físicas índice de refração e densidade a $20^{\circ} \mathrm{C}$ e os desvios padrões obtidos entre as triplicatas das medidas das propriedades.

Tabela 2 - Frações mássicas e propriedades físicas da curva binodal do sistema óleo de semente de girassol (1), n-hexanal (2) e lactato de etila (3) a $20^{\circ} \mathrm{C}$ a pressão atmosférica.

\begin{tabular}{|c|c|c|c|c|c|c|c|c|c|c|c|}
\hline \multicolumn{9}{|c|}{ Fase diluente rica em óleo de semente de } & \multicolumn{5}{c|}{ Fase extrato rica em lactato de etila } \\
\hline $100 \mathrm{w}_{1}$ & $100 \mathrm{w}_{2}$ & $\mathrm{nD}$ & $\begin{array}{c}\sigma^{\mathrm{a}} \\
\left(\mathrm{x} 10^{-5}\right)\end{array}$ & $\begin{array}{c}\rho \\
\left(\mathrm{g} / \mathrm{cm}^{3}\right)\end{array}$ & $\begin{array}{c}\sigma^{\mathrm{a}} \\
\left(\mathrm{x} 10^{-5}\right)\end{array}$ & $100 \mathrm{w}_{1}$ & $100 \mathrm{w}_{2}$ & $\mathrm{nD}$ & $\begin{array}{c}\sigma^{\mathrm{a}} \\
\left(\mathrm{x} 10^{-5}\right)\end{array}$ & $\begin{array}{c}\rho \\
\left(\mathrm{g} / \mathrm{cm}^{3}\right)\end{array}$ & $\begin{array}{c}\sigma^{\mathrm{a}} \\
\left(\mathrm{x} 10^{-5}\right)\end{array}$ \\
\hline 66,57 & 0 & 1,4535 & 12,1 & 0,95129 & 47,1 & 5,51 & 0 & 1,4165 & 0,58 & 1,02526 & 0,58 \\
\hline 66,64 & 0 & 1,4533 & 15 & 0,95125 & 1,5 & 5,17 & 0 & 1,416 & 29 & 1,02592 & 3,9 \\
\hline 64,62 & 0,65 & 1,4503 & 15 & 0,95319 & 1,5 & 6,54 & 0,97 & 1,4167 & 52 & 1,02321 & 4,9 \\
\hline 62,22 & 1,27 & 1,4505 & 5,8 & 0,95395 & 0,58 & 6,2 & 1,01 & 1,4168 & 0,58 & 1,02364 & 0 \\
\hline 61,77 & 1,29 & 1,4502 & 38 & 0,95318 & 0,56 & 7,98 & 1,87 & 1,418 & 21 & 1,01828 & 3,1 \\
\hline 60,15 & 1,86 & 1,4498 & 15 & 0,95577 & 1,5 & 7,52 & 1,95 & 1,4178 & 12 & 1,01852 & 1 \\
\hline 59,76 & 1,87 & 1,4491 & 5,9 & 0,95484 & 0,58 & 8,3 & 2,77 & 1,4181 & 5,8 & 1,01699 & 23 \\
\hline 56,85 & 2,41 & 1,4465 & 12 & 0,95807 & 1,2 & 7,85 & 2,82 & 1,418 & 5,8 & 1,01806 & 17 \\
\hline 46,96 & 3,55 & 1,4415 & 15 & 0,96633 & 2,6 & 15,74 & 4,97 & 1,422 & 5,8 & 0,99998 & 2,5 \\
\hline 51,19 & 3,27 & 1,4444 & 65 & 0,96013 & 2 & 14,78 & 5,06 & 1,4217 & 5,8 & 1,00356 & 4 \\
\hline
\end{tabular}

a: $\sigma$ : triplicata obtida entre as medidas das propriedades físicas.

Os coeficientes das Equações 1 e 2 ajustados aos dados experimentais apresentados na Tabela 2 estão expostos na Tabela 3. A partir destes parâmetros, os desvios médios relativos e os coeficientes de determinação entre os dados experimentais e calculados para as fases refinado e extrato foram, respectivamente, $5,92 \%$ e $2,62 \%$ e 0,9439 e 0,9947 .

Tabela 3 - Coeficientes de ajuste para as equações da curva binodal para o sistema óleo de semente de girassol (1), n-hexanal (2) e lactato de etila (3) a $20^{\circ} \mathrm{C}$.

\begin{tabular}{|c|c|c|c|c|c|c|}
\hline A & B & C & D & E & F & G \\
\hline$-0,7261$ & 5,2288 & $-13,6806$ & 15,5794 & $-4,9123$ & $-3,2171$ & 1,6748 \\
\hline
\end{tabular}




\subsection{Determinação das linhas de amarração e teste de qualidade dos dados}

Os dados do equilíbrio líquido-líquido do sistema óleo de semente de girassol (1), nhexanal (2) e lactato de etila (3) a $20^{\circ} \mathrm{C}$ sob pressão atmosférica obtidos pelo método da regra da alavanca estão apresentados na Tabela 4, sendo apresentados em um diagrama de fases em coordenadas retangulares na Figura 1.

Tabela 4 - Concentrações mássicas das linhas de amarração (LA) do sistema óleo de girassol (1), n-hexanal (2) e lactato de etila (3) a $20{ }^{\circ} \mathrm{C}$ obtidos pelo método da regra da alavanca.

\begin{tabular}{|c|c|c|c|c|c|c|c|}
\hline \multirow{2}{*}{ LA } & \multicolumn{2}{|c|}{ Mistura inicial } & \multicolumn{2}{|c|}{ Fase refinado } & \multicolumn{2}{|c|}{ Fase extrato } & \multirow{2}{*}{$\alpha$} \\
\cline { 2 - 7 } & $100 \mathrm{w}_{1}$ & $100 \mathrm{w}_{2}$ & $100 \mathrm{w}_{1}$ & $100 \mathrm{w}_{2}$ & $100 \mathrm{w}_{1}$ & $100 \mathrm{w}_{2}$ & \\
\hline 1 & 37,15 & 0,98 & 64,04 & 0,89 & 6,59 & 1,09 & 0,468 \\
\hline 2 & 35,94 & 1,49 & 63,21 & 1,09 & 7,23 & 1,91 & 0,487 \\
\hline 3 & 37,09 & 2,03 & 61,74 & 1,43 & 8,11 & 2,74 & 0,540 \\
\hline
\end{tabular}

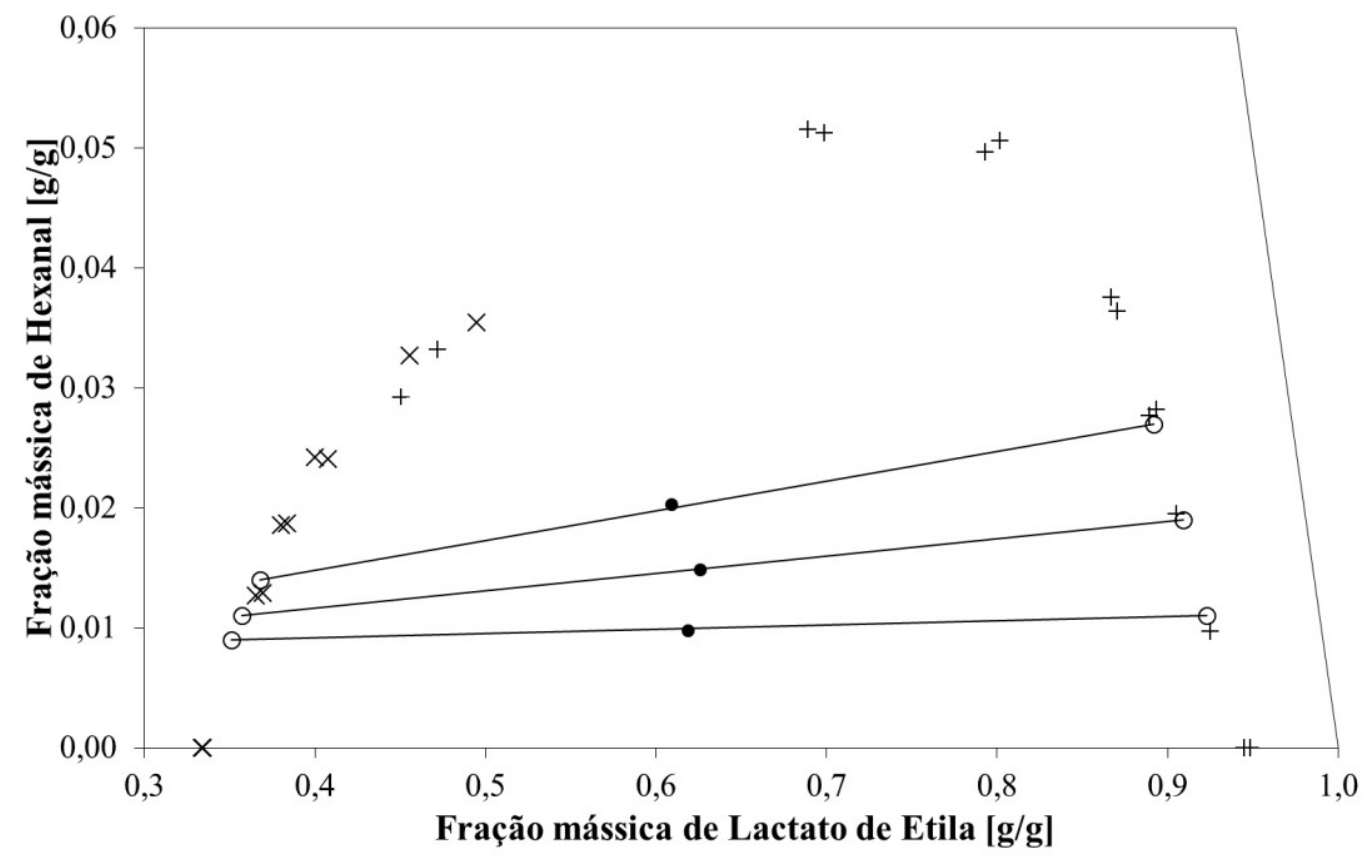

Figura 1 - Diagrama do equilíbrio líquido-líquido do sistema óleo de semente de girassol (1), n-hexanal (2) e lactato de etila (3) a $20^{\circ} \mathrm{C}$ : linhas de amarração ( $\left.\bullet-\right)$; ponto de mistura (•); curva binodal fase extrato $(+)$; curva binodal fase refinado $(\times)$.

Como observa-se na Figura 1, a extração do composto odorífero utilizando um solvente líquido é facilitada pelo fato das linhas de amarração apresentarem uma leve inclinação no sentido da fase extrato, indicando que o n-hexanal solubiliza-se mais facilmente no solvente do que no diluente. Os coeficientes de distribuição do soluto e a seletividade do solvente foram iguais a 1,22 e 11,9 para a LA (1) 1,73 e 15,2 para a LA (2) e 1,93 e 14,7 para a LA (3), respectivamente. Os dados do equilíbrio líquido-líquido do sistema óleo de semente 
de girassol (1), n-hexanal (2) e lactato de etila (3) a $20{ }^{\circ} \mathrm{C}$ apresentados na Tabela 4 resultaram em um coeficiente de determinação para os testes de qualidade de Othmer-Tobias e Hand de 0,975 e 0,968, respectivamente, indicando uma boa qualidade dos dados experimentais obtidos para as linhas de amarração.

\section{CONCLUSÕES}

Os dados experimentais para o equilíbrio líquido-líquido do sistema óleo de semente de girassol (1), n-hexanal (2) e lactato de etila (3) a $20{ }^{\circ} \mathrm{C}$ e sob pressão atmosférica indicaram a possibilidade de extrair o composto odorífero utilizando esse solvente líquido, com bons coeficientes de distribuição para o soluto e seletividade do solvente, ainda que a solubilidade de diluente na fase extrato seja elevada (maior que $30 \%$ ).

\section{REFERÊNCIAS BIBLIOGRÁFICAS}

BATISTA, E. et al. Liquid-liquid Equilibrium for Systems of Canola Oil, Oleic Acid and Short Chain Alcohols. J. Chem. Eng. Data, v. 44, p. 1360-64, 1999.

CUEVAS, M. S.; RODRIGUES, C. E. C.; MEIRELLES, A. J. A. Effect of Solvent Hydration and Temperature in the Deacidification Process of Sunflower oil using Ethanol. J. Food Eng., v. 95, p. 291-97, 2009.

GONÇALVES, C. B.; MEIRELLES, A. J. A. Liquid-Liquid Equilibrium Data for the System Palm Oil + Fatty Acids + Ethanol + Water at 318.2K. Fluid Phase Equilibria, v. 221, p. 139-50, 2004.

HAMM, W. Oil Production and Processing. In: CABALLERO, B. Encyclopedia of Food Sciences and Nutrition. 2. ed. Harpenden: Academic Press, 2003. p. 5904-416.

HAND, D. B. Dineric Distribution. Journal of Physical Chemistry, v. 34, p. 1961-2000, 1930.

MERCHUK J. C.; ANDREWS B. A.; ASENJO J. A. Aqueous two-phase systems for protein separation. Studies on phase inversion. J. Chromatography B Biomedicine Science Applied, v. 26, p. 285-93, 1998.

OTHMER, D. F.; TOBIAS, P. E. Tie-line Correlation. Industrial and Engineering Chemistry, v. 34, p. 693-6, 1942.

RODRIGUES, C. E. C. et al. Deacidification of Vegetable Oils by Solvent Extraction. Recent Patents on Engineering, v. 1, p. 95-102, 2007.

Agradecimentos: Os autores agradecem à FAPESP, ao CNPq pelo suporte financeiro e bolsas individuais. 